\title{
Relações de Causalidade no Padrão de Crescimento Industrial no Brasil (1975-2003)
}

\section{Causality Relations in the Industrial Growth Pattern in Brazil (1975-2003)}

Bernardo Patta Schettini* Ário Maro de Andrade** Márcio Antônio Salvato***

\begin{abstract}
Resumo: O objetivo central do artigo foi identificar as relações de precedência temporal no âmbito da produção industrial no período 1975-2003 por meio de testes de causalidade Granger, em que foi utilizada a classificação por categorias de uso (bens intermediários, não duráveis de consumo, duráveis de consumo e de capital). Em particular, buscou-se verificar se as relações de liderança e defasagem que se apresentaram com clareza durante o "milagre brasileiro" persistiram durante o período em questão. Na ocasião, quando o desaquecimento na demanda por duráveis arrastava os demais setores, a acumulação e a produção corrente na indústria de bens de capital finalmente cresciam. Isso foi interpretado como sendo um problema de realização dinâmica ou demanda efetiva. Os principais resultados do presente estudo emergiram de um modelo de vetores autorregressivos com mecanismo de correção de erro (VECM) e indicaram que a produção na indústria de bens de capital secundou os movimentos em bens de consumo duráveis no período, reproduzindo em larga medida o padrão observado durante o "milagre". Assim, o consumo conspícuo pareceu conduzir a indústria e a economia em seu conjunto por espasmos de crescimento.
\end{abstract}

Palavras-chave: Bens de capital. Bens duráveis de consumo. Causalidade Granger.

Abstract: The main purpose of this paper was to identify the time preceding relations in the industrial production during 1975-2003, by the means of Granger causality tests. To that end, we have adopted the classification by categories of primary use (intermediate, consumer non-durable, consumer durable and capital goods). Specifically, we aimed to verify whether the distinct outcomes for the

\footnotetext{
* Mestrando em economia pelo Cedeplar/UFMG. O autor agradece o apoio financeiro fornecido pela Capes. E-mail: bernardo.schettini@gmail.com

** Professor assistente III do Iceg/PUC-Minas e doutorando em economia pelo IE-Unicamp. E-mail: ariomaro@pucminas.br

*** Professor adjunto do IBMEC-Minas e professor visitante do programa de doutorado da EPGE/ FGV-RJ. E-mail: marcio.salvato@gmail.com
} 
leadership and lagging relations that were a sharp characteristic of the Brazilian "miracle" have persisted. While the slowdown in the demand for consumer durables dragged the other sectors, the accumulation and production in the capital goods industry were finally growing. That was interpreted as a dynamic realization or effective demand problem. The main results of the present investigation emerged from a vector error correction model (VECM) and indicated that the production in the capital goods industry have lagged the movements in the consumer durables in the period, reproducing to a large extent the pattern observed during the growth "miracle". Thus, conspicuous consumption seemed to drive industry and the economy as whole through growing spasms.

Keywords: Capital goods. Consumer durable goods. Granger causality.

JEL Classification: C32; O14.

\section{Introdução}

O postulado da demanda efetiva, pedra angular dos trabalhos de Keynes e Kalecki, ocupou lugar de destaque na discussão acadêmica das décadas de 1970 e 1980 no Brasil. Sem embargo, o axioma ganha sua mais importante dimensão em um contexto de implicações dinâmicas. Nesse sentido, Tavares (1998), Tavares e Belluzzo (1984), Serra (1984), além de Mello e Belluzzo (1984) identificam problemas de ordem estrutural que configuram uma crise de realização dinâmica na etapa de desaceleração do "milagre brasileiro" (1967-73), a partir de 1973/74.

Com base no esquema dinâmico trissetorial proposto por Kalecki (1968) é possível identificar a natureza pró-cíclica dos gastos em bens de consumo, principalmente não duráveis (bens de consumo assalariado). Ademais, uma vez que as flutuações na eficiência marginal do capital são entendidas como determinantes dos movimentos cíclicos (KEYNES, 1936), esperar-se-ia que a produção corrente da indústria de bens de capital precedesse temporalmente a variação nas indústrias de bens de consumo, inclusive duráveis, cabendo um teste de causalidade dinâmica.

Contudo, a relação de liderança e defasagem no âmbito da produção industrial brasileira pareceu contradizer essa lógica, sobretudo a partir de 1973/74. Na ocasião, enquanto o desaquecimento na demanda por duráveis de consumo arrastava os demais setores pela via das articulações interindustriais, a acumulação e a produção corrente de bens de capital finalmente cresciam. Isso posto, cabe ressaltar a incapacidade da indústria de consumo de duráveis em liderar o crescimento.

Este trabalho propõe identificar se o adverso padrão de crescimento, em que a produção corrente da indústria de bens duráveis de consumo cresce e traz a reboque bens de capital, cessa com o último esforço declarado de substituição de importações (II PND) ou estende-se até recente 
data. Para tanto, propõe-se um estudo da dinâmica intertemporal de 1975 a 2003 da produção (em quantum) de bens duráveis de consumo (BDC) e de bens de capital (BK), no sentido de buscar as relações de causalidade, pressupondo endogeneidade. Além disso, entendendo que tais dinâmicas não podem ser independentes das demais categorias de uso - bens intermediários (BI) e bens não duráveis de consumo (BNDC) -, constrói-se um modelo vetorial autorregressivo para analisar as dinâmicas de curto e longo prazos (cointegração).

Como principal resultado destaca-se o retardo temporal da produção de bens de capital em relação às indústrias de bens de consumo duráveis e não duráveis, vinculado ao princípio da demanda efetiva: as expansões de demanda no consumo se antecipam à expansão da oferta que requer aquisição de novas máquinas e equipamentos.

O restante do artigo foi organizado da seguinte maneira. A seção 2 apresenta uma discussão sobre o padrão cíclico do crescimento brasileiro de 1956 a 1976. A seção 3 mostra a metodologia empregada no trabalho para testar a relação de precedência temporal entre a produção corrente de bens de capital e a de duráveis de consumo no período 1975-2003. Essa mesma seção expõe os resultados dos testes de causalidade Granger no âmbito de um modelo do tipo vector error correction (VECM). Por fim, em uma última seção, são apresentadas as principais conclusões do trabalho.

\section{Dinâmica Industrial e seus Limites (1956-1976)}

O período que se estende de 1956 a 1976 é época fértil em transformações, conquanto rica em contradições. Estas são esclarecidas a seguir, a partir de uma exposição em que a sequência cronológica é preservada. Maior atenção foi dispensada ao período 1967-76, quando o problema de realização dinâmica e seus determinantes se apresentam com maior clareza.

\subsection{Aceleração (1956-61)}

A segunda metade da década de 1950 é marcada por forte crescimento, sustentado pela tríade capital estatal, capital multinacional e capital privado nacional, essencial para estabelecer as bases para um período de aceleração associado a importantes transformações estruturais. O sucesso do Plano de Metas (1956-61) é traduzido em taxas de crescimento bastante significativas e relativa estabilidade nos preços. Por outro lado, o pragmatismo do programa condiciona o instrumental de política econômica no sentido de postergar desequilíbrios externos e internos que, no limiar da década de 1960, repercutiriam sobre a balança de pagamentos 
e o nível de preços, culminando ademais em excessivos desgastes político e social.

Serra (1984, p. 77) sugere que entre 1955 e 1962, auge do ciclo, a produção de bens de capital e de duráveis de consumo tenha crescido a uma taxa anual média de 26,4 e 23,9\%, respectivamente. Entretanto, a reduzida participação desses setores na produção corrente da indústria de transformação (ver Tabela 1) no período acaba por levantar dúvidas acerca da liderança sobre o processo de crescimento. Nota-se que a participação de não duráveis na produção é, de longe, a mais significativa. Não obstante, esse setor apresenta um comportamento eminentemente pró-cíclico - respondendo aos estímulos da massa salarial. Esta, por sua vez, adquire maior robustez no auge do processo de acumulação que, por seu turno, é induzido pela crescente taxa de investimento nos setores líderes, conforme a lógica do esquema trissetorial de Kalecki (1968). Ou seja, o crescimento do consumo dos trabalhadores depende dos gastos dos capitalistas em consumo e investimento, conforme destacam Tavares e Belluzzo (1984, p. 126).

Tabela 1 - Estrutura da Produção na Indústria de Transformação (part.\%) no Brasil (1949-1980)

\begin{tabular}{l|c|c|c|c|c}
\hline \multicolumn{1}{c|}{ Categorias de uso } & $\mathbf{1 9 4 9}$ & $\mathbf{1 9 5 9}$ & $\mathbf{1 9 7 0}$ & $\mathbf{1 9 7 5}$ & $\mathbf{1 9 8 0}$ \\
\hline Bens de consumo não duráveis & 72,80 & 56,70 & 45,00 & 36,80 & 34,40 \\
\hline Bens intermediários & 20,40 & 24,60 & 34,40 & 34,60 & 37,40 \\
\hline Bens duráveis de consumo & 2,50 & 5,10 & 9,30 & 13,30 & 13,50 \\
\hline Bens de capital & 4,30 & 13,50 & 11,30 & 15,40 & 14,70 \\
\hline \multicolumn{1}{c|}{ Total } & $\mathbf{1 0 0 , 0 0}$ & $\mathbf{1 0 0 , 0 0}$ & $\mathbf{1 0 0 , 0 0}$ & $\mathbf{1 0 0 , 0 0}$ & $\mathbf{1 0 0 , 0 0}$ \\
\hline
\end{tabular}

Fonte: Adaptado de Serra (1984, p. 60).

De acordo com Serra (1984, p. 77), a evolução da indústria de bens intermediários deve ser entendida a partir de suas relações com os setores de demanda final. Nesse sentido, o seu desempenho, variação anual média de 12,1\% entre 1955 e 1962 e crescente participação na formação de capital, reflete o maior dinamismo naquelas indústrias privilegiadas pela acumulação.

Contudo, apesar do dinamismo do setor de bens de capital, ao final do ciclo expansivo sua oferta não havia sido, por completo, internalizada. As novas exigências do processo de acumulação, que derivam da mudança qualitativa na indústria nacional, acabam por frustrar a endogeneização da oferta. A procura por itens de maior componente tecnológico era, e continuaria a ser, suprida por importações. Mazzucchelli (1977) explica que esse aspecto em particular configurar-se-ia como uma limitação interna à autodeterminação do capital. 
Se de um lado as articulações inter-departamentais [sic] estimulam a sua expansão (a reboque dos demais setores), de outro, a expressiva participação dos oligopólios internacionais no sistema industrial (inclusive no próprio setor de bens de capital) implica que o suprimento ampliado de máquinas e equipamentos esteja obrigatoriamente mediatizado pelo esquema da divisão internacional do trabalho desse tipo de bens (MAZZUCCHELLI, 1977, p. 79).

Nesse sentido, a indústria de bens de capital, embora com crescente peso no conjunto da indústria de transformação, reproduzia um hiato tecnológico resultante de uma escolha política de basear o processo de industrialização num programa de substituição de importações com economia fechada.

\subsection{Desaceleração Inflacionária (1962-66)}

A desaceleração do crescimento (ver Tabela 2), apesar de reforçada por objetivos de política econômica de curto prazo, obedece a uma dinâmica cíclica e guarda severa relação com o recente desenvolvimento industrial. A deterioração dos ambientes político e social deve ser entendida antes como uma consequência dos desequilíbrios então experimentados do que como causa dos mesmos.

Tabela 2 - Comportamento dos Preços e do Produto (var.\%, média anual) no Brasil (1957-1976)

\begin{tabular}{c|c|c|c|c|c}
\hline Variável & $\mathbf{5 7 - 6 1}$ & $\mathbf{6 2 - 6 6}$ & $\mathbf{6 7 - 7 0}$ & $\mathbf{7 1 - 7 3}$ & $\mathbf{7 4 - 7 6}$ \\
\hline Deflator Implícito & 23,79 & 61,82 & 22,34 & 22,86 & 36,54 \\
\hline PIB (preços constantes) & 9,25 & 3,91 & 8,45 & 12,41 & 7,84 \\
\hline
\end{tabular}

Fonte: IBGE, Estatísticas do século XX: Sistema de Contas Nacionais Consolidadas.

Diversos fatores concorrem para condicionar a desaceleração: evolução da relação capital/produto; sobreinvestimento nos setores dominantes; deterioração da balança de pagamentos; escassez de fontes de financiamento internas e externas e, como causa e consequência, a aceleração inflacionária. Estatísticas relativas ao deflator implícito acusam repetidos acréscimos na inflação a partir de 1961, saltando de uma média anual de 23,79\% em 1957-61 para 61,82\% em 1962-67 (ver Tabela 2) e atingindo uma máxima de 89,9\% em 1964.

Os esquemas de estabilização propostos, Plano Trienal (1963) e Programa de Ação Econômica do Governo (PAEG, 1965-67), são motivados pelo recrudescimento da inflação, que não mais opera como válvula de escape, dirimindo seu constrangimento na euforia do crescimento. "A inflação perdeu sua serventia direta. A aceleração inflacionária passou a ser um resíduo indesejável e impeditivo da montagem de esquemas alternativos de financiamento de empresas e governo [...]" (LESSA, 1981, p. 122). 


\subsection{Recuperação, Auge e Desequilibrio (1967-73)}

A partir de 1967 a economia brasileira experimenta novo ciclo expansivo, uma vez mais sustentado pela solidariedade entre os interesses internos e externos. Suas principais características relacionam-se a precedentes de natureza exógena, a saber: a concentração da renda urbana, além das reformas fiscal e financeira. ${ }^{1}$ Ademais, à transição presidencial seguiu uma reorientação na condução da política econômica, por sua vez privilegiada pela liquidez internacional, com importantes implicações sobre o crescimento. Entretanto, os determinantes de ordem estrutural não parecem ser tão precisos.

Nesta subseção, são discutidos os principais aspectos que garantem a esta etapa a qualidade de responder pelo período de crescimento mais robusto na história de industrialização nacional, bem como acumular desequilíbrios que se apresentariam com clareza já na desaceleração a partir de 1974 e, de forma bastante pronunciada, na crise dos anos 80. Cabe destacar que os movimentos que configuram as etapas de recuperação (1967-70) e desaceleração (1974-76) não guardam fiel relação com as teorias do ciclo sustentadas pelo comportamento do investimento.

A despeito das taxas de crescimento no período do "milagre" (1967-73) serem próximas às observadas no Plano de Metas (1956-61), a realidade é marcadamente distinta. Às transformações institucionais somar-se-iam condições conjunturais favoráveis, sem as quais o auge não se manifestaria de forma tão intensa.

Em contraste com o observado no Plano de Metas, o "milagre" coincide com significativa abertura da economia - em que pesem a ampliação e a diversificação das exportações, acompanhadas de substancial melhora nos termos de intercâmbio, além do crescente fluxo de financiamento externo e dos incentivos às importações de máquinas e equipamentos. A indústria, uma vez mais, apresenta crescimento apreciável, acima do produto global da economia (ver Tabela 3). De acordo com Mello e Belluzzo (1984, p. 148), embora as estatísticas acusem crescimento superior ao observado na ocasião do Plano de Metas, não mais se identifica um "bloco de inversões" que processe algo similar a uma "onda" de inovações concentrada. Ainda, enquanto em etapa anterior o setor de bens de produção assumia papel determinante no ciclo, por ora "o eixo de acumulação passou a repousar sobre o setor de bens duráveis de consumo - basicamente automóveis e construção civil”.

1 Transformações relativas ao Plano de Ação Econômica do Governo (PAEG, 1964-66). Para mais detalhes, ver Abreu (1990, cap. 9). 
Tabela 3 - Variação Anual Média do Produto Real (em \%) por Setores - Brasil (1957-1976)

\begin{tabular}{l|c|c|c|c|c}
\hline Classes e Ramos de Atividade Econômica & $\mathbf{5 7 - 6 1}$ & $\mathbf{6 2 - 6 6}$ & $\mathbf{6 7 - 7 0}$ & $\mathbf{7 1 - 7 3}$ & $\mathbf{7 4 - 7 6}$ \\
\hline Agropecuária & 5,79 & 2,53 & 4,66 & 4,65 & 3,44 \\
\hline Indústria & - & - & - & 14,33 & 8,34 \\
\hline Extrativa mineral & 13,69 & 13,23 & 11,52 & 5,20 & 9,27 \\
\hline Transformação & 11,30 & 3,81 & 9,78 & 14,13 & 7,84 \\
\hline Construção & 8,19 & 3,97 & 11,22 & 17,05 & 9,12 \\
\hline Serviços industriais de utilidade pública & 8,33 & 8,07 & 9,32 & 12,95 & 12,27 \\
\hline Serviços Total & - & - & - & 13,07 & 9,02 \\
\hline \multicolumn{1}{c}{$\quad$} & $\mathbf{9 , 2 5}$ & $\mathbf{3 , 9 1}$ & $\mathbf{8 , 4 5}$ & $\mathbf{1 2 , 4 1}$ & $\mathbf{7 , 8 4}$ \\
\hline
\end{tabular}

Fonte: IBGE, Estatísticas do século XX: Sistema de Contas Nacionais Consolidadas.

A ampliação das margens de endividamento das famílias, promovida no âmbito da reforma financeira, cumpre reanimar a procura por duráveis de consumo e alguns artigos de consumo assalariado (vestuário, por exemplo), já a partir de 1966-67. Ademais, à crescente burocratização da grande empresa - que se estende ao setor público, a quem cabe gerir uma economia do tipo monopólica de Estado - corresponde uma realimentação da demanda por duráveis de consumo, reforçada pelo encurtamento dos prazos de obsolência (diferenciação de produtos e manipulação publicitária). O Sistema Financeiro de Habitação, por sua vez, proporciona as condições de liquidez necessárias aos gastos em habitação. Na verdade, a indústria da construção valeu-se ainda da maior procura engendrada pelas empresas públicas - as quais foram favorecidas pelo maior realismo tarifário e pela alternativa ao endividamento externo.

Nesse sentido, a produção de duráveis de consumo vale-se de uma demanda efetiva que precede a retomada dos investimentos. Observa-se, inclusive, um substancial declínio na relação capital/produto dessa indústria em particular que, de acordo com Serra (1984), responde não só pelas amplamente conhecidas economias de escala, mas também pela redução nos preços relativos das máquinas e equipamentos. Tavares (1998, p. 87) observa ainda que, no auge, a indústria de duráveis é a que "mais se beneficia da queda de preços relativos dos seus componentes mecânicos e dos bens de capital".

Assim, enquanto a produção de bens de consumo apresenta salutar dinamismo a partir de 1967, o setor de bens de capital só mostra desempenho similar em princípios da década de 1970 (ver Tabela 4). Assim, [...] o setor de bens de capital ocupa uma posição subordinada dentro do sistema industrial [...] sua expansão é, ademais, reflexa, e não obedece a uma política de desenvolvimento" (MAZZUCCHELLI, 1977, p. 80, grifo nosso). 
Tabela 4 - Evolução Anual Média de Bens de Capital e Duráveis de Consumo (em \%) no Brasil (1957-1975)

\begin{tabular}{c|c|c|c|c}
\hline \multirow{2}{*}{ Períodos } & \multirow{2}{*}{$\begin{array}{c}\text { Bens Duráveis } \\
\text { de Consumo (BDC) }\end{array}$} & \multicolumn{3}{|c}{ Bens de Capital (BK) } \\
\cline { 3 - 5 } & 25,50 & 29,19 & 21,65 & Produção \\
\hline $1957-61$ & 6,10 & 3,17 & 1,97 & $-3,80$ \\
\hline $1962-66$ & 21,33 & 10,74 & 12,97 & 21,57 \\
\hline $1967-70$ & 21,77 & 25,11 & 24,50 & 22,54 \\
\hline $1971-73$ & 9,52 & 9,58 & 13,26 & 24,43 \\
\hline $1974-75$ & & & & \\
\hline
\end{tabular}

Fonte: Adaptado de Mazzucchelli (1977).

Mello e Belluzzo (1984) explicam que a produção de bens de capital estaria sujeita a problemas de escala. No que diz respeito à demanda por essa mesma categoria de bens, Mazzucchelli (1977) destaca a crescente participação das importações na oferta interna, principalmente no caso dos bens de capital de produção seriada, porquanto a oferta interna apresenta evolução de capacidade de produção e de atualização tecnológica que não mais atendem às exigências de acumulação engendradas pelas recentes expansão e diferenciação do parque produtivo nacional.

A abundante oferta de capitais financeiros internacionais, apoiada em uma legislação que favorece a captação externa de recursos em moeda, atua em favor das decisões de investir, mantendo elevada a relação investimento/PIB no período e com aumento da participação de capital externo no setor de bens duráveis de consumo. Algo similar se verifica no caso do setor de insumos básicos, não obstante a dominância das estatais. De acordo com Mazzucchelli (1977), uma vez que a acumulação interna não proporciona o montante líquido necessário à consecução dos programas de inversão, o recurso aos empréstimos externos apresenta-se como a opção mais adequada do ponto de vista das decisões de empresas. Tal opção, por seu turno, "passa a configurar uma estrutura de financiamento que condiciona a estrutura de compras das empresas estatais", sendo a exportação preferencial a de mercadorias, em detrimento da de capitais (Idem, p. 81).

A partir de 1970 o setor de bens de capital apresenta as mais altas taxas de crescimento setorial, em grande medida respondendo aos estímulos oriundos da demanda derivada da indústria de duráveis de consumo. Serra (1984, p. 92) acrescenta que

[...] em fins de 1970 as autoridades econômicas se deram conta do desequilíbrio potencial existente e procuraram eliminá-lo, mediante incentivos aos investimentos privados e realização de investimentos públicos diretos na indústria de bens de capital e insumos básicos. 
A produção de não duráveis também apresenta evolução notória, acompanhando a demanda associada à ampliação da massa salarial. Com efeito, no auge (1970-73) as relações entre os departamentos industriais mostram-se especialmente dinâmicas, uma vez que praticamente cessa a capacidade ociosa herdada do período anterior.

\subsection{Desaceleração e Manifestação de Desequilibrios (1974-76)}

Muito embora a produção de duráveis de consumo apresente taxas de crescimento bastante elevadas, já a partir de 1972 esse setor revela sinais de desaceleração. De acordo com Mello e Belluzzo (1984, p. 151), a indústria em questão é incapaz de promover um crescimento autogerado, o que deriva da "fratura entre a ampliação da sua taxa de acumulação e o crescimento da sua demanda efetiva".

A expansão da indústria de bens de capital esbarraria na adversa natureza da acumulação recente, o que, em última análise, caracterizaria uma crise de realização dinâmica, segundo Mello e Belluzzo (1984). Apesar da taxa de acumulação nesse setor ter se ampliado a partir de 1974, sobretudo sob os estímulos do II Plano Nacional de Desenvolvimento (II PND), Tavares (1998) explica que sua dimensão relativa seria incapaz de suscitar uma demanda autônoma que reanimasse os demais setores por efeito de encadeamento.

No auge (1970-73), a indústria de transformação, de um modo geral, apresentava acentuada taxa de acumulação. Entretanto, fica patente a assincronia entre o crescimento da produção corrente das indústrias de duráveis de consumo vis-à-vis bens de capital. Segundo Mello e Belluzzo (1984), as taxas de acumulação evoluem em sentido intrigante: enquanto

[...] o declínio da taxa de acumulação do setor de duráveis de consumo começa a arrastar os demais setores, já no final de 1973, [...] a capacidade instalada da indústria de bens de produção estava se ampliando (MELLO; BELLUZZO, 1984, p. 154).

É interessante observar o que ocorre no caso dos bens não duráveis de consumo. Sua participação relativa é indubitavelmente a mais significativa no conjunto da indústria, ainda que declinante. A crescente massa de salários favorece sua expansão nas etapas de recuperação e auge. Todavia, o crescimento do emprego não mais acompanha a evolução da produção corrente, já que depende muito pouco da acumulação na indústria pesada e o setor de construção experimenta oscilações a partir de 1974. Ademais, o salário real apresenta majorações aquém dos acréscimos na produtividade e, já em 1973, tende a declinar em termos reais. Por fim, resta esclarecer que não se verifica, no período, um export-drive 
que configure uma demanda efetiva capaz de engendrar altas taxas de crescimento - o que é especialmente verdadeiro com o desaquecimento do comércio internacional e a abrupta alteração nos termos de troca em 1974. Na verdade, a menor rentabilidade esperada tende a conduzir esse setor, do mesmo modo que os duráveis de consumo, à redução em seu nível de atividade a partir de 1974.

Segundo Tavares (1998), a crise da desaceleração pós-1974 não se manifestou de forma estrita até o fim da década, sendo o investimento público global o maior responsável pela manutenção da elevada taxa de inversões e por um crescimento do produto próximo à média histórica do pós-guerra. De acordo com Serra (1984, p. 107), "[...] o sustentáculo principal dos investimentos foi o setor público - o governo até 1976 e as empresas públicas até 1979 [...]". Entretanto, a inadequada forma de articulação com o exterior implicaria crescente endividamento associado a um processo de especulação nas órbitas financeira e real da economia - resultando em focos de tensão e manifestação adiantada dos constrangimentos que adviriam de forma mais acentuada posteriormente na chamada crise da dívida externa da década de 1980.

\section{Padrão de Crescimento Industrial Recente (1975-2003)}

A segunda metade da década de 1970 corresponde ao último esforço declarado de substituição de importações. Uma vez mais, a desaceleração que segue o ciclo expansivo resulta em desequilíbrios de ordem interna e externa. Além do mais, o choque de petróleo e o galope da dívida externa garantem maiores proporções à desaceleração. De uma forma geral, a década de 1980 responde pelo período em que o recurso aos planos de estabilização acaba por criar novos mecanismos de automatismo inflacionário e especulativo. Outrossim, a instabilidade que se processa no lado real da economia se confunde com sua mais severa forma de manifestação na esfera financeira: a espiral inflacionária.

$\mathrm{Na}$ década de 1990, a indústria nacional experimenta importantes transformações, as quais guardam estreita relação com a abertura comercial e com as privatizações. Todavia, a excessiva valorização da moeda nacional, inerente à estratégia de estabilização do Plano Real, termina por conduzir a economia brasileira a um grande ajuste, com taxas de crescimento reduzidas, expansão da dívida interna e dificuldade de geração de saldos comerciais, mas compensado pela entrada de capitais estrangeiros. Com a liberação do câmbio em 1999, não se observou a temível volta da inflação, garantida pelo cenário recessivo, advindo de política monetária apertada. Contudo, a demanda externa entra num "boom" de crescimento a partir dos anos 2000, puxada pelo crescimento 
acelerado de China e Índia, com alta procura por commodities que sustenta o crescimento da economia brasileira. Novos rumos são estabelecidos a partir de uma política de receituário ortodoxo que se inicia em 1999, com um programa de metas de inflação.

Não obstante as mudanças promovidas na estrutura da produção, a economia brasileira reproduz, em época recente, características advindas de sua estratégia de desenvolvimento de décadas anteriores, associada a um programa de substituição de importações e economia fechada, conferindo um hiato tecnológico e uma baixa produtividade. Apesar disso, houve ganhos em produtividade e mudanças na estrutura produtiva com a abertura comercial no início da década de 1990.

\subsection{Modelo Empirico: Causalidade Granger}

O emprego da abordagem estatística requer uma reinterpretação da noção de causalidade entre variáveis. É oportuno esclarecer que não se trata de uma relação de causa e efeito pura, no sentido literal da palavra. Na verdade, o que sustenta a ideia de causalidade é a precedência temporal no âmbito de um modelo preditivo.

O teste de Granger parte da premissa de que o futuro não pode causar o passado. Se um evento Granger-causa outro, uma mudança na variável explicativa deve preceder temporalmente a respectiva variação induzida na variável dependente. Todavia, o fato de um evento preceder o outro no tempo não implica necessariamente causalidade. Mais precisamente, se os valores defasados de uma certa variável (x) melhoram a predição da variável dependente (y), tem-se que x causa y no sentido de Granger. Alternativamente, se o contrário é válido, y Granger-causa x. No caso de ambos os resultados serem verificados, infere-se em favor de uma relação de mútua dependência (feedback) em vez de líder-defasagem. ${ }^{2}$ Se, entretanto, nenhum resultado é estatisticamente significativo, não se conclui na direção de nenhuma relação de causa ou dependência entre as variáveis.

É salutar esclarecer que a leitura dos resultados dos testes não deve prescindir de uma teoria que justifique sua aplicação. Entretanto, entende-se que a discussão até aqui estendida estabeleça um nexo entre a investigação empírica e a teoria econômica.

\subsubsection{Raiz Unitária e Ordem de Integração}

Granger e Newbold (1974) alertam que as séries macroeconômicas são, em geral, integradas (não estacionárias, com tendência estocástica) e

2 Estes são, respectivamente, equivalentes a: causalidade em duplo sentido ( $\mathrm{x} \leftrightarrow \mathrm{y}$ ) e causalidade unívoca $(\mathrm{x} \rightarrow \mathrm{y})$ - as setas indicando o sentido da relação de precedência temporal. 
que a regressão a partir de seus respectivos níveis pode conduzir a resultados espúrios - à medida que tende a reproduzir uma relação significativa entre variáveis ditas independentes a partir dos usuais parâmetros t e $\mathrm{F}^{3}{ }^{3}$ A evidência da má especificação do modelo seria, nesse caso, expressa pela não-estacionariedade dos resíduos.

Estudar a presença de raiz unitária em uma série é o mesmo que testar sua estacionariedade. Para tanto, utiliza-se o teste Aumentado de Dickey e Fuller (ADF), amplamente aceito e empregado na literatura. Sua forma geral é expressa pela seguinte equação:

$$
\Delta y_{t}=\alpha_{0}+\beta t+(\rho-1) y_{t-1}+\sum_{i=1}^{k-1} \theta_{i} \Delta y_{t}-i+a_{t}
$$

em que $\Delta=(1-\mathrm{L})$, sendo $\mathrm{L}$ o operador de defasagem $\left(\mathrm{LY}_{\mathrm{t}}=\mathrm{Y}_{\mathrm{t}-1}\right)$, $t$ a tendência (determinística) e $a_{\mathrm{t}}$ um termo aleatório, ruído branco. Caso a hipótese nula de não estacionariedade $\left(\mathrm{H}_{0}: \rho=1\right)$ não possa ser rejeitada, deve-se proceder na diferenciação até que a série se torne estacionária. Entretanto, cumpre antes verificar se as variáveis relevantes são cointegradas. Nesse caso particular, a diferenciação não seria necessária, implicando, inclusive, perda de informação.

\subsubsection{Cointegração e a Equação do Teste}

Séries que apresentam raiz unitária podem, ainda, no contexto de uma ou mais combinações lineares entre variáveis, mostrarem-se estacionárias. Nesse sentido, a possibilidade de cointegração, que exprima uma relação estável de longo prazo, deve ser considerada. Além disso, desvios da relação estável de longo prazo representam informação relevante para a previsão da variação de curto prazo das séries.

Para tanto, adota-se uma regressão cointegrante, do tipo:

$$
\mathrm{yt}_{\mathrm{t}}=\alpha_{0}+\theta \mathrm{x}_{\mathrm{t}}+\mathrm{et}_{\mathrm{t}}
$$

em que x e y são integradas de mesma ordem. ${ }^{4} \mathrm{~A}$ partir dessa regressão, testa-se a raiz unitária das estimativas dos resíduos $\left(\hat{e}_{t}\right)$. Se $e_{t}$ for I(0) - leia-se estacionário -, conclui-se que as variáveis x e y são cointegradas e empregase um mecanismo de correção de erro (ECM) quando da aplicação dos

3 De acordo com Wooldridge (2002, cap. 18), estudos que se iniciam em Granger e Newbold (1974) apontam para uma inadequação das estatísticas t e F diante de uma especificação do modelo em que as variáveis sejam não estacionárias. Sendo x e y independentes, a regressão de uma em função da outra se mostra estatisticamente relevante em uma frequência bem maior (acima de 65\% das vezes) do que a esperada (nível de significância do teste). A equação cointegrante pode também conter um termo de tendência determinística. 
testes de causalidade. Nesse caso, as regressões pertinentes assumem a seguinte forma:

$$
\begin{aligned}
& \Delta \mathrm{y}_{\mathrm{t}}=\alpha_{0}+\delta_{1}\left(\mathrm{y}_{\mathrm{t}-1-\gamma} \mathrm{X}_{\mathrm{t}-1}\right)+\sum_{\mathrm{i}=1}^{\mathrm{k}} \alpha_{1 \mathrm{i}} \Delta \mathrm{y}_{\mathrm{t}-\mathrm{i}}+\sum_{\mathrm{i}=1}^{\mathrm{k}} \alpha_{2 \mathrm{i}} \Delta \mathrm{x}_{\mathrm{t}-\mathrm{i}}+\mathrm{U}_{1 \mathrm{t}} \\
& \Delta \mathrm{x}_{\mathrm{t}}=\beta_{0}+\delta_{2}\left(\mathrm{yt}_{\mathrm{t}-1}-\gamma_{\mathrm{xt}-1}\right)+\sum_{\mathrm{i}=1}^{\mathrm{k}} \beta_{1 \mathrm{i}} \Delta \mathrm{y}_{\mathrm{t}}-\mathrm{i}+\sum_{\mathrm{i}=1}^{\mathrm{k}} \beta_{2 \mathrm{i}} \Delta \mathrm{x}_{\mathrm{t}}-\mathrm{i}+\mathrm{U}_{2 \mathrm{t}}
\end{aligned}
$$

em que $\delta_{1}$ e $\delta_{2}$ representam as velocidades de ajustamento das séries para desvios da tendência de longo prazo. No entanto, se a regressão dos resíduos não indicar a presença de cointegração, o teste deve valer-se das seguintes equações:

$$
\begin{aligned}
& \Delta \mathrm{y}_{\mathrm{t}}=\alpha_{0}+\sum_{\mathrm{i}=1}^{\mathrm{k}} \alpha_{1 \mathrm{i}} \Delta \mathrm{y}_{\mathrm{t}}-\mathrm{i}+\sum_{\mathrm{i}=1}^{\mathrm{k}} \alpha_{2 \mathrm{i}} \Delta \mathrm{x}_{\mathrm{t}}-\mathrm{i}+\mathrm{v}_{1 \mathrm{t}} \\
& \Delta \mathrm{x}_{\mathrm{t}}=\beta_{0}+\sum_{\mathrm{i}=1}^{\mathrm{k}} \beta_{1 \mathrm{i}} \Delta \mathrm{y}_{\mathrm{t}}-\mathrm{i}+\sum_{\mathrm{i}=1}^{\mathrm{k}} \beta_{2 \mathrm{i}} \Delta \mathrm{x}_{\mathrm{t}} \mathrm{i}+\mathrm{v}_{2 \mathrm{t}}
\end{aligned}
$$

Finalmente, no caso mais simples, em que não se verifica a presença de raiz unitária nas séries, parte-se de:

$$
\begin{aligned}
& \mathrm{y}_{\mathrm{t}}=\alpha_{0}+\sum_{\mathrm{i}=1}^{\mathrm{k}} \alpha_{1 \mathrm{i}} \mathrm{y}_{\mathrm{t}}-\mathrm{i}+\sum_{\mathrm{i}=1}^{\mathrm{k}} \alpha_{2 \mathrm{i}} \mathrm{X}_{\mathrm{t}-\mathrm{i}}+\mu_{1 \mathrm{t}} \\
& \mathrm{X}_{\mathrm{t}}=\beta_{0}+\sum_{\mathrm{i}=1}^{\mathrm{k}} \beta_{1 \mathrm{i}} \mathrm{y}_{\mathrm{t}}-\mathrm{i}+\sum_{\mathrm{i}=1}^{\mathrm{k}} \beta_{2 \mathrm{i}} \mathrm{Xt}_{\mathrm{t}} \mathrm{i}+\mu_{2 \mathrm{t}}
\end{aligned}
$$

em que as regressões são estimadas a partir das variáveis em seus respectivos níveis.

Resta, a partir dos três conjuntos de equações apresentados, considerar os possíveis testes de hipóteses sobre a dependência temporal do conjunto de variáveis. Se não se rejeita a hipótese $H_{0}: \alpha_{21}=\alpha_{22}=\ldots=\alpha_{2 \mathrm{k}}=0$ e $\delta_{1}=0$, então x não Granger-causa y. Do mesmo modo, se $\mathrm{H}_{0}: \beta_{11}=\beta_{12}=\ldots=\beta_{1 \mathrm{k}}=0$ e $\delta_{2}=0$ não é rejeitada, y não causa x no sentido Granger. Caso a hipótese nula seja rejeitada em apenas um dos casos, conclui-se em favor de uma relação de causalidade unívoca, líder-defasagem. Se, por outro lado, em ambos os casos a hipótese nula é abandonada, conclui-se que há uma relação de simultaneidade, feedback. 


\subsection{Evidência Empírica}

Nesta etapa procurou-se investigar a respeito de uma possível relação de precedência temporal entre a produção corrente de bens duráveis de consumo (BDC) e a de bens de capital (BK). As séries para as demais categorias de uso, bens intermediários (BI) e bens não duráveis de consumo (BNDC), foram introduzidas no modelo com vistas a captar as demais relações causais.

Em um primeiro momento são apresentadas as principais características das séries. A aplicação dos testes de causalidade segue criteriosamente a metodologia mostrada anteriormente. Portanto, a ordem de integração das séries e os vetores de cointegração, reproduzidos respectivamente a partir de processos estocásticos do tipo autoregressivo (AR) e vetores autoregressivos (VAR), são apresentados nas Tabelas 5 e 6. Os testes de Granger, já no contexto de um modelo vetorial com correção de erro (VECM), encontram-se no fim desta seção.

\subsubsection{Análise e Tratamento das Séries}

A abordagem empírica vale-se dos índices mensais de quantum produzido por categorias de uso para a indústria nacional de 1975 até 2003 . $^{5}$ A forma de agregação atende à manutenção da perspectiva analítica até então utilizada que privilegia a identificação de relações entre atividades cuja produção tem uso diferenciado.

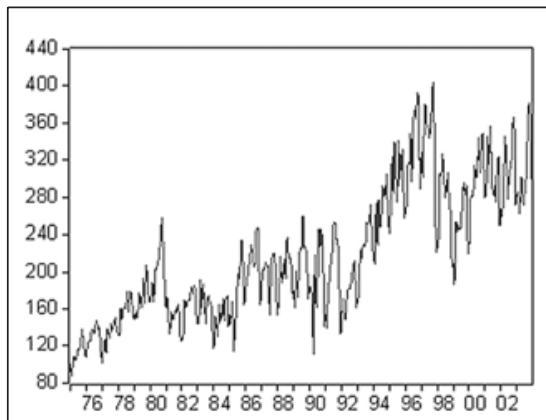

Gráfico 1 - BDC-Índice Mensal de Quantum Produzido (1975:01=100) - Brasil - 1975-2003

Fonte: IBGE, PIM-PF antiga.

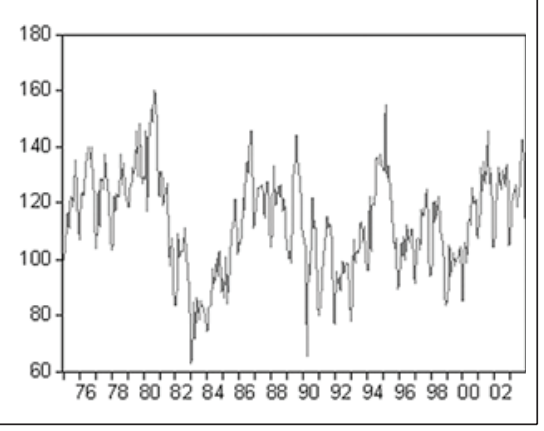

Gráfico 2-BK-Índice Mensal de Quantum Produzido $(1975: 01=100)$ - Brasil - 1975-2003

Fonte: IBGE, PIM-PF antiga.

5 Ipeadata: dados macroeconômicos. Fonte primária de dados: IBGE, Pesquisa Industrial Mensal - Produção Física (PIM-PF antiga). 


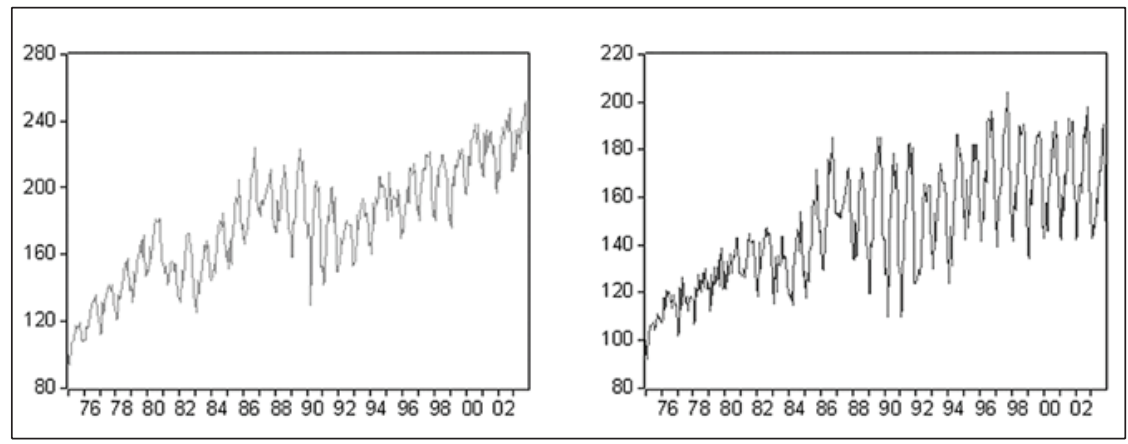

Gráfico 3-BI-Índice Mensal de Quantum Produzido (1975:01 = 100) - Brasil - 19752003

Gráfico 4 - BNDC - Índice Mensal de Quantum Produzido (1975:01=100) Brasil - 1975-2003

Fonte: IBGE, PIM-PF antiga.

Fonte: IBGE, PIM-PF antiga.

No período em questão, a estrutura produtiva brasileira foi alterada de forma qualitativa, além de ter sido submetida a diversos contratempos de ordens interna e externa. Uma vez que se admita a presença de tendência determinística, a verificação de quebra estrutural reclama um ajuste nos dados. Entretanto, no presente trabalho, optou-se pela modelagem com o argumento de tendência estocástica, porquanto não parece claro como os choques afetam deterministicamente as tendências. Contudo, se esse for o caso (tendência determinística com quebra estrutural), então a validade dos testes pode ser colocada em xeque. ${ }^{6}$ É importante ressaltar que essa limitação, inerente à aproximação adotada, é reconhecida.

A seguir são apresentados os resultados do teste ADF para todas as séries. A escolha do número de defasagens pelo critério de informação de Schwarz segue uma orientação parcimoniosa, com vistas a evitar a sobreparametrização e a perda de graus de liberdade.

Tabela 5 - Teste ADF para Todas as Categorias de Uso

\begin{tabular}{l|c|c|c}
\hline \multicolumn{1}{c|}{$\mathbf{H}_{\mathbf{0}}$ : Raiz Unitária } & \multicolumn{1}{c}{ Especificaçãó } & Teste ADF & P-valor** $^{*}$ \\
\hline BDC (level) & trend, constant, 12 lags. & -2.794817 & 0.2002 \\
\hline BDC (1 $1^{\text {st }}$ difference) & no trend, no constant, 11 lags. & -6.075305 & 0.0000 \\
\hline BK (level) & no trend, constant, 12 lags. & -2.843942 & 0.0533 \\
\hline BK (1 $1^{\text {st }}$ difference) & no trend, no constant, 12 lags. & -4.415545 & 0.0000 \\
\hline BI (level) & trend, constant, 12 lags. & -2.746407 & 0.2187 \\
\hline
\end{tabular}

6 Ver Perron (1990; 1997) e Perron e Vogelsang (1992).

SCHETTINI, B. P.; ANDRADE, A. M.; SALVATO, M. A. Relações de causalidade no padrão... 
(continuação)

\begin{tabular}{l|c|c|c}
\hline BI $\left(1^{\text {st }}\right.$ difference $)$ & no trend, no constant, 11 lags. & -6.033725 & 0.0000 \\
\hline BNDC (level) & no trend, constant, 12 lags. & -2.273845 & 0.1812 \\
\hline BNDC (1 $1^{\text {st }}$ difference) & no trend, no constant, 11 lags. & -7.803785 & 0.0000 \\
\hline
\end{tabular}

*lag escolhido com base no critério de informação de Schwarz.

**p-valor calculado com base em Mackinnon (1996).

Fonte: Elaborada pelos autores.

No caso das variáveis em nível, não se rejeita a hipótese nula de raiz unitária para nenhuma das séries. Entretanto, tomadas as primeiras diferenças, os processos estocásticos mostram-se estacionários - ou seja, todas as séries de produto industrial por categorias de uso são I(1), leia-se estacionárias em primeira diferença.

Cumpre ainda verificar a existência de cointegração entre as variáveis. Os resultados para o teste de Johansen encontram-se, de forma sumária, na Tabela 6. Em sua parte inferior é apresentada a resultante equação de cointegração.

Tabela 6 - Teste Johansen para Cointegração e Equação Cointegrante

\section{Séries: BDC, BK, BI, BNDC.}

Especificação: no deterministic trend, constant, 2 lags. *

\begin{tabular}{|c|c|c|c|c|c|c|c|}
\hline \multirow{3}{*}{$\begin{array}{c}\mathrm{H}_{0} \text { para vetores } \\
\text { de cointegração ** }\end{array}$} & \multirow{3}{*}{ Eigenvalue } & \multicolumn{3}{|c|}{ Trace Statistic } & \multicolumn{3}{|c|}{ Max-Eigen Statistic } \\
\hline & & \multirow{2}{*}{$\begin{array}{l}\text { Estatística } \\
\text { do teste }\end{array}$} & \multicolumn{2}{|c|}{ Valor crítico } & \multirow{2}{*}{$\begin{array}{l}\text { Estatística } \\
\text { do teste }\end{array}$} & \multicolumn{2}{|c|}{ Valor crítico } \\
\hline & & & $5 \%$ & $1 \%$ & & $5 \%$ & $1 \%$ \\
\hline Nenhum & 0.218093 & 117.2662 & 47.21 & 54.46 & 84.87681 & 27.07 & 32.24 \\
\hline No máximo 1 & 0.049960 & 32.38942 & 29.68 & 35.65 & 17.68160 & 20.97 & 25.52 \\
\hline No máximo 2 & 0.033350 & 14.70782 & 15.41 & 20.04 & 11.70192 & 14.07 & 18.63 \\
\hline No máximo 3 & 0.008675 & 3.005901 & 3.76 & 6.65 & 3.005901 & 3.76 & 6.65 \\
\hline \multicolumn{4}{|c|}{ Equação cointegrante ${ }^{* * *}$} & BDC & BI & BK & BNDC \\
\hline \multicolumn{4}{|c|}{ Coeficientes normalizados de cointegração } & 1.00000 & 3.237371 & -2.170446 & -9.133072 \\
\hline \multicolumn{4}{|c|}{ Desvio-padrão associado } & - & 0.66176 & 0.55201 & 0.95954 \\
\hline
\end{tabular}

*lag escolhido com base no critério de informação de Schwarz $\left(\mathrm{SC}_{\min }=29,16794\right)$.

**A 1\% de significância, rejeita-se a hipótese nula de nenhum vetor de cointegração - seja pela estatística max-eigen ou trace. No último caso, a 5\% de significância, rejeita-se ainda a hipótese nula de no máximo um vetor de cointegração.

***No caso de apenas um vetor de cointegração.

Fonte: Elaborada pelos autores.

Muito embora as séries sejam individualmente I(1), os resultados para o teste de cointegração indicam a presença de uma combinação linear entre as variáveis que é estacionária. Ademais, a 5\% de significância e a partir da estatística trace, poder-se-ia considerar a presença de dois ve- 
tores de cointegração. Entretanto, diante da não-unanimidade nos resultados, optou-se por considerar apenas uma equação cointegrante. Logo, conclui-se em favor de uma relação estável de longo prazo entre as variáveis e, por conseguinte, é possível reproduzir uma especificação de correção de erro (VECM).

O teste de causalidade Granger deve seguir a especificação expressa pela equação (3). Além da significância conjunta dos coeficientes para as defasagens das variáveis relevantes, a significância do coeficiente relativo ao mecanismo de correção de erro (ECM), correspondente à equação cointegrante estimada, também se mostra importante. Os resultados para o sistema estimado encontram-se na Tabela 7.

Tabela 7 - Processo Multivariado com Correção de Erro

\begin{tabular}{|c|c|c|c|c|}
\hline \multicolumn{5}{|c|}{ Vector Error Correction (VECM) } \\
\hline \multirow{2}{*}{$\begin{array}{c}\text { Variáveis } \\
\text { explicativas* }\end{array}$} & \multicolumn{4}{|c|}{ Variáveis dependentes } \\
\hline & $\mathrm{D}(\mathrm{BDC})$ & $\mathrm{D}(\mathrm{BK})$ & $\mathrm{D}(\mathrm{BI})$ & $\mathrm{D}(\mathrm{BNDC})$ \\
\hline $\begin{array}{c}\text { Equação } \\
\text { cointegrante }\end{array}$ & $\begin{array}{r}0.058445 \\
(0.01702) \\
{[3.43377]}\end{array}$ & $\begin{array}{r}0.028699 \\
(0.00553) \\
{[5.18924]}\end{array}$ & $\begin{array}{r}0.048825 \\
(0.00633) \\
{[7.71468]}\end{array}$ & $\begin{array}{r}0.055201 \\
(0.00646) \\
{[8.54765]}\end{array}$ \\
\hline $\mathrm{D}(\mathrm{BDC}(-1))$ & $\begin{array}{r}-0.306509 \\
(0.08286) \\
{[-3.69916]}\end{array}$ & $\begin{array}{r}0.003364 \\
(0.02692) \\
{[0.12495]}\end{array}$ & $\begin{array}{r}-0.074114 \\
(0.03081) \\
{[-2.40553]}\end{array}$ & $\begin{array}{r}-0.068830 \\
(0.03144) \\
{[-2.18933]}\end{array}$ \\
\hline $\mathrm{D}(\mathrm{BDC}(-2))$ & $\begin{array}{r}-0.279928 \\
(0.08407) \\
{[-3.32967]} \\
\end{array}$ & $\begin{array}{r}-0.077276 \\
(0.02732) \\
{[-2.82884]} \\
\end{array}$ & $\begin{array}{r}-0.027204 \\
(0.03126) \\
{[-0.87023]}\end{array}$ & $\begin{array}{r}-0.029382 \\
(0.03190) \\
{[-0.92110]}\end{array}$ \\
\hline $\mathrm{D}(\mathrm{BK}(-1))$ & $\begin{array}{r}-0.483978 \\
(0.26599) \\
{[-1.81955]}\end{array}$ & $\begin{array}{r}-0.340681 \\
(0.08643) \\
{[-3.94181]}\end{array}$ & $\begin{array}{c}0.215705 \\
(0.09890) \\
{[2.18096]}\end{array}$ & $\begin{array}{r}-0.022738 \\
(0.10092) \\
{[-0.22530]}\end{array}$ \\
\hline $\mathrm{D}(\mathrm{BK}(-2))$ & $\begin{array}{r}-0.111445 \\
(0.26402) \\
{[-0.42210]}\end{array}$ & $\begin{array}{c}-0.213105 \\
(0.08579) \\
{[-2.48405]}\end{array}$ & $\begin{array}{r}-0.128315 \\
(0.09817) \\
{[-1.30703]}\end{array}$ & $\begin{array}{r}-0.209466 \\
(0.10018) \\
{[-2.09094]}\end{array}$ \\
\hline $\mathrm{D}(\mathrm{BI}(-1))$ & $\begin{array}{r}0.886678 \\
(0.29551) \\
{[3.00054]}\end{array}$ & $\begin{array}{r}0.389645 \\
(0.09602) \\
{[4.05799]}\end{array}$ & $\begin{array}{r}-0.194903 \\
(0.10988) \\
{[-1.77378]}\end{array}$ & $\begin{array}{r}-0.082470 \\
(0.11212) \\
{[-0.73553]}\end{array}$ \\
\hline $\mathrm{D}(\mathrm{BI}(-2))$ & $\begin{array}{r}1.301705 \\
(0.30012) \\
{[4.33725]}\end{array}$ & $\begin{array}{r}0.390044 \\
(0.09752) \\
{[3.99966]}\end{array}$ & $\begin{array}{r}0.252747 \\
(0.11160) \\
{[2.26484]}\end{array}$ & $\begin{array}{r}0.339900 \\
(0.11387) \\
{[2.98485]}\end{array}$ \\
\hline $\mathrm{D}(\mathrm{BNDC}(-1))$ & $\begin{array}{r}-0.201967 \\
(0.28551) \\
{[-0.70739]}\end{array}$ & $\begin{array}{r}-0.229549 \\
(0.09277) \\
{[-2.47437]}\end{array}$ & $\begin{array}{c}0.083742 \\
(0.10616) \\
{[0.78881]}\end{array}$ & $\begin{array}{r}0.278817 \\
(0.10833) \\
{[2.57377]}\end{array}$ \\
\hline $\mathrm{D}(\mathrm{BNDC}(-2))$ & $\begin{array}{r}-0.388410 \\
(0.30292) \\
{[-1.28224]}\end{array}$ & $\begin{array}{c}0.005170 \\
(0.09843) \\
{[0.05253]}\end{array}$ & $\begin{array}{c}0.088616 \\
(0.11263) \\
{[0.78675]}\end{array}$ & $\begin{array}{r}0.177088 \\
(0.11493) \\
{[1.54077]}\end{array}$ \\
\hline
\end{tabular}


(continuação)

\begin{tabular}{c|c|c|c|c}
\hline $\mathrm{R}^{2}$ ajustado & 0.192511 & 0.252566 & 0.247348 & 0.264380 \\
\hline Estatística F & 11.25150 & 15.53020 & 15.13128 & 16.45410 \\
\hline P-valor & 0.000232 & 0.000060 & 0.000067 & 0.000047 \\
\hline
\end{tabular}

*Para cada coeficiente estimado são apresentados: o desvio-padrão em parênteses e a estatística do teste t em colchetes.

Fonte: Elaborada pelos autores.

Todas as regressões mostram-se estatisticamente relevantes a $1 \%$ de significância (ver estatísticas F e p-valores na Tabela 7). Muito embora o coeficiente de determinação ajustado ( $R^{2}$ ajustado) seja menor que $0,3 \mathrm{em}$ todos os casos, a modelagem pelo VECM não reproduz nenhuma relação espúria entre as variáveis - o que valida os resultados para o teste de Granger apresentados a seguir.

\subsubsection{Resultados e análises}

A partir dos testes de causalidade não se pode rejeitar a hipótese de um retardo temporal na produção corrente da indústria de BK (ver Tabela 8). Mais precisamente, BDC e BNDC causam BK no sentido Granger - sendo o $\mathrm{p}$-valor referente à relação de causalidade unívoca $\mathrm{BDC} \rightarrow \mathrm{BK}$ próximo de $1 \%$. Nesse sentido, a expansão da indústria de BK secunda os movimentos nas indústrias de bens de consumo, sobretudo no caso dos duráveis.

A partir dos testes entre BK e BI, percebe-se uma relação de simultaneidade na produção corrente das duas indústrias (BI $\leftrightarrow$ BK) - o que retrata uma dinâmica interindustrial, restrita ao departamento I (bens de produção), favorável.

Tabela 8 - Testes de Granger para Precedência Temporal

\begin{tabular}{l|c|c|l}
\hline \multicolumn{1}{c|}{ Hipótese nula } & Chi-square & $\begin{array}{c}\text { P-valor } \\
\text { (Teste Wald) }\end{array}$ & \multicolumn{1}{c}{ Conclusão } \\
\hline BK não Granger-causa BDC & 3.340487 & 0.1882 & Não se rejeita a hipótese nula \\
\hline BI não Granger-causa BDC & 22.28035 & 0.0000 & Rejeita-se a hipótese nula \\
\hline BNDC não Granger-causa BDC & 2.192077 & 0.3342 & Não se rejeita a hipótese nula \\
\hline BDC não Granger-causa BK & 8.527905 & 0.0141 & Rejeita-se a hipótese nula \\
\hline BI não Granger-causa BK & 25.37351 & 0.0000 & Rejeita-se a hipótese nula \\
\hline BNDC não Granger-causa BK & 6.122594 & 0.0468 & Rejeita-se a hipótese nula \\
\hline BDC não Granger-causa BI & 5.932138 & 0.0515 & Não se rejeita a hipótese nula \\
\hline BK não Granger-causa BI & 9.256899 & 0.0098 & Rejeita-se a hipótese nula \\
\hline BNDC não Granger-causa BI & 1.273574 & 0.5290 & Não se rejeita a hipótese nula \\
\hline BDC não Granger-causa BNDC & 5.022750 & 0.0812 & Não se rejeita a hipótese nula \\
\hline
\end{tabular}




\begin{tabular}{l|l|l|l}
\hline BK não Granger-causa BNDC & 4.595226 & 0.1005 & Não se rejeita a hipótese nula \\
\hline BI não Granger-causa BNDC & 11.58264 & 0.0031 & Rejeita-se a hipótese nula \\
\hline
\end{tabular}

Fonte: Elaborada pelos autores.

Os resultados para os testes entre $\mathrm{BK}$ e $\mathrm{BDC}$ reclamam algumas considerações mais elaboradas. A indústria de BDC vale-se de uma demanda efetiva que favorece sua expansão antes que virtuais estímulos nas indústrias de BK e BI, oriundos de novas decisões de investir, processem-se e sejam veiculados. Assim, os estímulos que governam as flutuações se manifestam antes na indústria de BDC e depois se espraiam pela economia em seu conjunto. A natureza oligopolista dessa indústria implica a opção estratégica por capacidade ociosa. Portanto, sua recuperação só produz efeitos induzidos sobre a produção de máquinas e equipamentos com certa defasagem.

Diante da natureza pró-cíclica da indústria de não duráveis, a rejeição da hipótese nula de que BNDC não Granger-causa BK oferece evidência renovada acerca do papel legado à indústria de bens de capital. Ou seja, a indústria de bens de capital se move pela demanda efetiva gerada nos setores de bens de consumo duráveis e não duráveis.

É interessante observar que BI Granger-causa BDC e, no caso de se adotar um nível de significância um pouco mais elevado, conclui-se que há uma relação de feedback (BI $\leftrightarrow \mathrm{BDC})$. Nesse sentido, a indústria de BDC apresenta importantes articulações com BI. Todavia, é importante ressaltar que até que se processasse a desestatização de parte da indústria de intermediários, a evolução em BI não obedecia a uma racionalidade econômica calcada na expectativa dos agentes quanto ao retorno do capital.

Em última análise, a partir dos resultados para os testes de causalidade, conclui-se que a economia nacional reproduz uma dinâmica interindustrial similar, em larga medida, àquela verificada para o período do "milagre". O problema da assincronia entre BK e BDC não cessa com as transformações promovidas a partir de 1975, sendo que BK apresenta um ciclo defasado.

\section{Considerações finais}

O atraso temporal na produção de bens de capital, relativamente a bens duráveis de consumo, apresenta-se com bastante clareza na ocasião do "milagre" econômico, na década de 1970. Esse comportamento obedece ao princípio de demanda efetiva, sendo que expansões de demanda nas indústrias de bens de consumo durável e não durável consolidam-se no instante seguinte em expansão da oferta de bens de capital. Contudo, a indústria de bens duráveis de consumo é incapaz de sustentar um crescimento autogerado, em uma concepção de corte Keynesiana ou Kaleckiana. 
Isso ocorre porque: (I) existe uma fratura entre a ampliação de sua taxa de acumulação e o crescimento da sua demanda efetiva (MELLO; BELLUZZO, 1984); (II) o aumento no estoque dessa categoria de bens se faz aos saltos (TAVARES, 1998).

Isso posto, o presente trabalho correspondeu a um esforço no sentido de produzir evidência empírica com respeito às relações de precedência temporal no âmbito da produção industrial para o período 1975-2003. Em particular, atenção especial foi dispensada ao comportamento das indústrias de bens duráveis de consumo e de capital. O método adotado foi o de testes causalidade Granger. O modelo VECM mostrou-se apropriado porque, embora as séries sejam I(1), existe uma relação estável de longo prazo entre as variáveis. Não obstante, é importante alertar que os resultados dos testes podem ser diferentes caso a hipótese de tendência estocástica, em detrimento de tendência determinística com quebras estruturais, não seja correta.

Os resultados para os testes de Granger corroboram, em grande medida, a noção de que a indústria nacional de bens de capital secunda os movimentos da indústria de bens duráveis de consumo. A relação entre bens de capital e bens não duráveis de consumo fornece evidência renovada com respeito ao papel subordinado legado à indústria de máquinas e equipamentos. Diversos fatores concorrem para engendrar uma dinâmica dessa natureza. Entrementes, os resultados são entendidos como corolário, principalmente: (I) das contradições imanentes à industrialização no Brasil; (II) da especialização no crédito ao consumo.

Um processo de industrialização marcado por uma política de substituição de importações com economia fechada e dependente fortemente de investimento estatal resultou num crescimento do setor de bens de capital que obedece a um retardo temporal em relação às expansões de demanda da indústria de bens de consumo durável e não durável. Soma-se a isso um cenário de inflação crescente que dificulta a formação de expectativas, inviabilizando os projetos de investimento que antecipem a demanda.

A especialização no crédito ao consumidor privilegia o consumo conspícuo às expensas dos gastos em bens de investimento. Ademais, é o que se espera num momento histórico de inflação crescente. Assim, a ausência de um eixo financeiro que favoreça a oferta de funding surge como outro importante fator explicativo. Contudo, o presente trabalho não reúne os elementos para uma conclusão definitiva nesse sentido. Na verdade, esse aspecto é pouco explorado na literatura.

Embora por vezes o cenário conjuntural anime estratégias de crescimento calcadas na importação de máquinas e equipamentos, é importante destacar a importância da endogeneização da oferta e dos mecanismos de atualização tecnológica na indústria que configura o seio da acumulação 
capitalista. Por fim, é interessante ressaltar a necessidade de uma reestruturação dos mecanismos de financiamento da economia na direção de se criar funding para o setor de bens de capital.

\section{Referências}

ABREU, M. P. A ordem do progresso: cem anos de política econômica republicana: 18891989. Rio de Janeiro: Campus, 1990.

BELLUZZO, L. G. M.; COUTINHO, R. Desenvolvimento capitalista no Brasil: ensaios sobre a crise. 3.ed. São Paulo: Brasiliense, 1984. v. 1.

GRANGER, C. W. J.; NEWBOLD, P. Spurious regression in econometrics. Journal of Econometrics, v. 2, n.2, p. 111-120, July 1974.

GREENE, W. H. Econometric analysis. 5. ed. New Jersey: Prentice Hall, 2003.

INSTITUTO BRASILEIRO DE GEOGRAFIA E ESTATÍSTICA. Estatísticas do século XX: sistema de contas nacionais consolidadas. Disponível em: <http://www.ibge.gov.br/> . Acesso em: $1^{\circ}$ mar. 2008.

INSTITUTO DE PESQUISA ECONÔMICA APLICADA. Ipeadata: dados macroeconômicos. Disponível em: < http://www.ipeadata.gov.br/> . Acesso em: 10 mar. 2008.

KALECKI, M. The marxian equations of reproduction and modern economics. Social Science Information, v. 7, n.6, p. 73-79, 1968.

KEYNES, J. M. The general theory of employment, interest and money. London: Macmillan, 1936.

LESSA, C. Quinze anos de política econômica. São Paulo: Brasiliense, 1981.

MACKINNON, J. G. Numerical distribution functions for unit root and cointegration tests. Journal of Applied Econometrics, v.11, n.6, p. 601-618, 1996.

MAZZUCCHELLI, F. M. A expansão inconclusa (considerações sobre o setor de bens de capital no Brasil). Dissertação (Mestrado em Economia) - Universidade Estadual de Campinas, Instituto de Economia, Campinas, 1977.

MELLO, J. M. C.; BELLUZZO, L. G. M. Reflexões sobre a crise atual. In: BELLUZZO, L. G. M.; COUTINHO, R. (Org.) Desenvolvimento capitalista no Brasil: ensaios sobre a crise. 3. ed. São Paulo: Brasiliense, 1984. v.1. p. 141-158.

PERRON, P. Testing for a unit root in a time series with a changing mean. Journal of Business E Economic Statistics, v. 8, n.2, p. 153-62, 1990.

Further evidence on breaking trend functions in macroeconomic variables. Journal of Econometrics, v. 80, n.2, p. 355-385, 1997.

PERRON, P.; VOGELSANG, T. J. Nonstationarity and level shifts with an application to purchasing power parity. Journal of Business \& Economic Statistics, v. 10, n.3, p. 301-20, 1992.

SERRA, J. Ciclos e mudanças estruturais na economia brasileira do pós-guerra. In: BELLUZZO, L. G. M.; COUTINHO, R. (Org.) Desenvolvimento capitalista no Brasil: ensaios sobre a crise. 3. ed. São Paulo: Brasiliense, 1984., v.1. p. 56-121.

TAVARES, M. C. Ciclo e crise: o movimento recente da industrialização brasileira. Campinas: UNICAMP, 1998. (Coleção 30 Anos de Economia, v. 8). 
TAVARES, M. C.; BELLUZZO, L. G. M. Notas sobre o processo de industrialização recente no Brasil. In: BELLUZZO, L. G. M.; COUTINHO, R. (Org.) Desenvolvimento capitalista no Brasil: ensaios sobre a crise. 3.ed. São Paulo: Brasiliense, 1984. v.1. p. 122-140.

WOOLDRIDGE, J M. Introductory econometrics: a modern approach. 2.ed. Cincinnati, OH: South-Western, 2002.

Recebido em: 23/11/2008.

Aceito em: 17/09/2009. 